\title{
Un acercamiento al papel de la educación en la teoría política de Thomas Hobbes ${ }^{*}$
}

\author{
ADRIANA ROCÍO TORRES SANABRIA**
}

Recepción: 10 de mayo de 2017

Aprobación: 22 de agosto de 2017

Forma de citar este artículo: Torres, A.R. (2018). Un acercamiento al papel de la educación en la teoría política de Thomas Hobbes. Cuadernos de Lingüística Hispánica, (33), 41-55.

doi $10.19053 / 0121053 X . n 33.2019 .8953$

* Artículo de reflexión derivado del proyecto de investigación "Concepciones de política", del año 2015, del grupo de investigación Filosofía, Sociedad y educación UPTC, en la línea ética y filosofía política.

** Docente Universidad Pedagógica y Tecnológica de Colombia, tesista Maestría en Filosofía del Derecho y Teoría Jurídica de la Universidad Libre. Correo electrónico: adrianarocio.torres@uptc.edu.co (iD https://orcid.org/ooooooo3-3420-6165 


\title{
Resumen
}

El presente escrito muestra una parte de las reflexiones que se han hecho -con base en autores de la modernidad, en este caso específico Thomas Hobbes- sobre el concepto de educación y el sentido que este filósofo le da dentro de su teoría política. Para esto, primero se establecerá el estado de naturaleza, pues se tiene que describir esa condición inicial en la que, según Hobbes, el hombre se encuentra y, en este sentido, analizar la función de la educación; luego se desarrollará la idea de pacto social como fundamento del Estado civil y, en último término, se indicará cuál es la función de la educación teniendo en cuenta el pensamiento de Hobbes, el hombre en su estado de naturaleza y lo que el pacto busca resolver.

Palabras clave: educación, estado civil, estado de naturaleza, pacto social.

\section{An Approach to the Role of Education in the Political Theory of Thomas Hobbes}

\begin{abstract}
This paper shows a part of the reflections that have been made, based on authors of the modernity, in this specific case Thomas Hobbes, on the concept of education and the sense that this philosopher gives to it within his political theory. For this, in the first place, the state of nature will be established, because that initial condition of the man, exposed by Hobbes, has to be described and, in this sense, to analyze the function of education; then the idea of social pact as the foundation of the Civil State will be developed, and finally the function of education is explained, taking into account Hobbes's thought, the man in his state of nature and what the pact seeks to solve.
\end{abstract}

Keywords: education, Civil State, state of nature, social pact. 


\section{Une approche au rôle de l'éducation dans la théorie politique de Thomas Hobbes}

\section{Résumé}

Cet article prétend montrer une partie des réflexions qui ont été faites, ayant comme base des auteurs de la modernité, dans ce cas spécifique, Thomas Hobbes, sur le concept d'éducation et le sens que Hobbes lui donne dans sa théorie politique. Pour cela, c'est l'état de nature qui sera établi tout d'abord, puisque l'on doit décrire cette condition initiale, dans laquelle, selon Hobbes, l'homme se retrouve et, dans ce sens, analyser la fonction de l'éducation. Ensuite, on développera l'idée de pacte social comme fondement de l'État civil, pour finalement montrer quelle est la fonction de l'éducation, en tenant compte de la considération de Hobbes, l'homme dans son état de nature et ce que le pacte cherche à résoudre.

Mots clés : Éducation, État civil, état de nature, pacte social.

\section{Uma abordagem ao papel da educação na teoria política de Thomas Hobbes}

\section{Resumo}

Este trabalho pretende mostrar uma parte das reflexões que foram feitas, baseadas em autores da modernidade, neste caso específico, Thomas Hobbes, sobre o conceito de educação e o significado que Hobbes lhe dá dentro de sua teoria política. Para isso, o que inicialmente será estabelecido será o estado de natureza, uma vez que essa condição inicial deve ser descrita na qual, de acordo con Hobbes, o homem é encontrado e, nesse sentido, analisar a função da educação; então a ideia de um pacto social será desenvolvida como a fundação do estado civil, para finalmente mostrar qual é a função da educação, levando em conta a consideração de Hobbes, o homem em seu estado de natureza e o que o pacto busca resolver.

Palavras-chave: Educação, Estado civil, estado de natureza, pacto social. 


\section{Introducción}

Al analizar y determinar cuestiones como las condiciones políticas de la modernidad, se vislumbra cómo los cambios que alcanza el dominio político se dan principalmente con la aparición de nuevas formas de poder, más centralizadas, de las cuales el Estado moderno es su máxima expresión. Su papel creciente y nuevas funciones, la difusión del imperio de la ley y la creciente inclusividad de la ciudadanía son característicos de un contexto marcado por la organización burocrática. En el campo de la cultura disminuye la importancia de las creencias y de los valores mágicos y religiosos, con un papel preponderante de la ciencia como proveedora del verdadero conocimiento, propio de prácticas productivas (Altini, 2005). Estos, entre otros elementos, hacen parte del momento en el que Hobbes sitúa su reflexión con relación al hombre y al Estado.

La modernidad sabe de la importancia de la educación, especialmente en la construcción del Estado, aunque no hay una referencia explícita en los grandes pensadores políticos, por ejemplo en Hobbes; sin embargo, él, que en su Leviatán considera al hombre egoísta, con miedo a morir, cuyo único objetivo es sobrevivir y que por su igualdad natural vive en guerra de todos contra todos, situación que hace que difícilmente prospere la sociedad tanto en la ciencia como en la cultura, sabe de la necesidad de superar esta condición y crear un poder común que imponga el orden mediante el temor y el castigo, poder común que surge del pacto hecho entre los hombres (Borón, 2000). Hobbes (1966) parte de una consideración negativa e incapaz del hombre para autodominarse, por eso requiere de la educación, pero ella sola no basta para resolver el problema, hace falta ser dominado mediante la fuerza.

El presente escrito muestra parte de las reflexiones que se han hecho a partir del estudio de algunas de las obras de Thomas Hobbes, específicamente lo referente al concepto de educación y el sentido que este le da dentro de su teoría política. La pertinencia de este escrito en particular está en la necesidad de conocer una época clave de la humanidad: la modernidad, pues esta se caracteriza por el privilegio que le da a la razón; un ejemplo de ello es la ciencia moderna (física y matemática) (Cassirer, 1953). En este sentido, el orden social no pudo escapar a esta pretensión científica, convirtiéndose a su vez en un problema puramente humano que debe ser pensado, por ejemplo, desde la política, pero no la política como un discurso puramente especulativo, sino con las características propias de la ciencia (Medina, 2014). Hobbes asume esa tarea, hacer una teoría sobre el Estado.

Teniendo en cuenta lo mencionado, inicialmente se indicará el estado de naturaleza, para poder analizar la función política y social de la educación, pues se tiene 
que establecer la consideración antropológica y, en este sentido, describir la función de la misma; luego se desarrollará la idea de pacto social como fundamento del Estado civil y, en último término, se mostrará cuál es la función de la educación, teniendo en cuenta la consideración antropológica de Hobbes y lo que el pacto busca resolver.

\section{El ser humano en su condición natural}

Lo primero que hay que tener en cuenta es qué clase de reflexión antropológica hace Hobbes sobre el ser humano, pues es el fundamento para poder establecer la sociedad civil. Así, en el Leviatán, El Ciudadano y en los Elementos del derecho natural y político, Hobbes considera al hombre como el resultado de una serie de facultades. En El Ciudadano las define en cuatro clases: la fuerza física, la experiencia, la razón y las pasiones (Sierra, 2011). Con este hombre poseedor de estas capacidades, Hobbes (1966) plantea si este es apto o no para vivir en comunidad y gracias a cuál facultad. Así pues, el hombre es capacidad de movimiento, capacidad de acción y de conocimiento, lo que implica la utilización de la sensación, la memoria y la imaginación. De esta manera, "la naturaleza del hombre es la suma de sus facultades y poderes naturales: tales son las facultades de nutrirse moverse, reproducirse, sentir razonar, etc." (Hobbes, 2005, p. 92).

Ahora bien, para Hobbes, el hombre, en su condición natural, es un ser que está en guerra, tiene miedo de los otros y por esa misma condición tiende a perjudicar a los otros en busca de defender lo que por derecho natural le corresponde. Hobbes (1966) no cree en una disposición natural de los hombres para convivir, al contario de Aristóteles, quien cree que esas disposiciones se adquieren y que, en principio, en cada hombre lo que hay es un sentimiento de conveniencia y de utilidad al buscar asociarse con los otros, porque en todos ellos está la idea de la defensa de la propia vida como el bien más preciado que cada uno tiene.

Este axioma, aunque aceptado por la mayoría de los autores, no deja de ser falso y el error proviene de un examen demasiado superficial de la naturaleza humana. Quienes examinen más detenidamente por qué los hombres se juntan y gozan de su compañía mutua comprobarán sin dificultad que no se debe a una ley inevitable de la naturaleza, sino a circunstancias fortuitas. En efecto, si el hombre amara al hombre por naturaleza, es decir, en cuanto hombre, ¿cómo se podría explicar que uno no ame igualmente a todos los hombres, sino que prefiere a aquellos cuya compañía le vale a él más consideración y ventajas que a otros? No, lo que buscamos por naturaleza, no son los compañeros, sino la consideración y las ventajas que nos ofrecen; deseamos éstas, antes que aquéllos. (Hobbes, 1966, p. 64)

En esta misma condición natural de guerra de todos contra todos reside el miedo mutuo que se da debido a la igualdad natural de los hombres. Esta igualdad natural es 
una representación original en Hobbes, "una afirmación totalmente realista, sin ninguna raíz en sistemas de valores, presupuestos religiosos o metafísicos" (Santillán, 1998, p. 21). Por esto, no podemos esperar la seguridad ni de nosotros mismos ni la de los otros. De esta manera, en esta condición natural la voluntad de perjudicase mutuamente se encuentra en todos, una de las causas de esto es que en ese estado todo está permitido; y la otra es por el hecho de algunos de creerse superiores a los demás atribuyéndose más honores. Sin embargo, se debe aclarar, como lo manifiesta Macpherson (1970), que no hay que entender al hombre natural contrapuesto al hombre civilizado, sino que Hobbes se refiere a los deseos de hombres civilizados, en este sentido, el estado de naturaleza sería una condición hipotética.

Ahora bien, Hobbes (1966) señala que la causa más frecuente del querer perjudicarse mutuamente es el deseo que todos tienen de una misma cosa, ya sea porque no se puede dividir o por no se puede disfrutar en común. Pero esta actitud es natural, "El hombre está inclinado a buscar lo bueno para él y a evitar lo malo, y particularmente la muerte que es el peor de los males naturales" (p. 68). Hacer esto no va en contra de la recta razón y, por tanto, es hecho con derecho, y según el derecho natural, cada uno conserva el derecho de juzgar cuáles son los medios adecuados que puede utilizar para proteger su vida y sus bienes, hasta tanto no aparezca otro ente superior que garantice su seguridad.

La naturaleza ha hecho a los hombres tan iguales en sus facultades de cuerpo y alma, que aunque puede encontrarse en ocasiones a hombres físicamente iguales más fuertes o mentalmente más agiles que otros, cuando consideramos todo junto, la diferencia entre hombre y hombre no es tan apreciable como para justificar el que un individuo reclame para sí cualquier beneficio que otro individuo no pueda reclamar con igual derecho. Pues, en lo que se refiere a fuerza corporal, el más débil tiene fuerza suficiente para matar al más fuerte, ya mediante maquinaciones secretas, o agrupado con otros que se ven en el mismo peligro que él [...]

De esta igualad en las facultades surge la esperanza de alcanzar nuestros fines. Y, por tanto, si dos hombres desean una misma cosa que no puede ser disfrutada por ambos, se convierten en enemigos; $y$, para lograr su fin, que es, principalmente, su propia conservación y, algunas veces, sólo su deleite, se empeñan en destruirse y someterse mutuamente. (Hobbes, 1994, pp. 105-106)

Ahora bien, Hobbes sabe que gracias a esas facultades o capacidades mencionadas anteriormente, en especial una, la razón, el hombre busca salir de esa condición miserable y odiosa. Lo que lo lleva inicialmente a plantearse la necesidad de las leyes naturales, leyes que se derivarían precisamente del uso de la recta razón. Él establece la búsqueda de la paz como la ley fundamental de la naturaleza, pues sabe que la condición de guerra, que deriva de sus pasiones, se opone precisamente a ese instinto de conservación. Y es así 
como estos preceptos morales, el derecho de todos a todo es insostenible, encaminan al hombre hacia la renuncia y la trasferencia de derechos a través del pacto social.

Porque las leyes de naturaleza, como la justicia, la equidad, la modestia, la misericordia y, en suma, el hacer con los demás los que quisiéramos que hiciese con nosotros, son en sí mismas, y cuando no hay terror a algún poder que obligue a observarlas, contrarias a nuestras pasiones naturales, las cuales nos inclinan a la parcialidad, al orgullo, a la venganza, y demás. Y los convenios cuando no hay temor a la espada, son sólo palabras que no tienen fuerza suficiente para dar a un hombre la menor seguridad. (Hobbes, 1994, p. 141)

Por la recta razón, los hombres buscan salir de este conflicto en el que se encuentran y realizar un pacto o unión que representaría el paso al Estado civil, que permita su autoconservación en una condición de seguridad permanente.

\section{La sociedad civil como resultado del pacto}

El surgimiento del Estado moderno permite, a través de Hobbes, buscar una nueva ciencia del hombre y del Estado. Hobbes marca una época en la historia de la ley natural y de la teoría del Estado. Concretamente, en el ámbito de la filosofía política, la pregunta por el poder que emana de las estructuras que encarnan el Estado ha sido frecuente entre los pensadores más distinguidos (Bobbio, 2003). A la luz de esta pregunta surge entonces la necesidad de legitimar estas estructuras con argumentos que provengan de la razón, en oposición a argumentos que justifiquen todo poder estatal a partir del derecho divino del rey, dando lugar así a modelos teóricos que tienen por objeto responder a este interrogante ¿Cuál es la fuente del poder estatal?

La lucha del Estado moderno es una larga y sangrienta lucha por la unidad del poder. Esta unidad es el resultado de un proceso a la vez de liberación y unificación: de liberación en su enfrentamiento con una autoridad de tendencia universal que por ser de orden espiritual se proclama superior a cualquier poder civil; y de unificación en su enfrentamiento con instituciones menores, asociaciones, corporaciones, ciudades, que constituyen en la sociedad medieval un peligro permanente de anarquía. Como consecuencia de estos dos procesos, la formación del estado moderno viene a coincidir con el reconocimiento y con la consolidación de la supremacía absoluta del poder político sobre cualquier otro poder humano. Esta supremacía recibe el nombre de soberanía. (Bobbio, 1992, p. 71)

El Estado aparece no como una realidad natural o una creación divina, sino como un acto voluntario y racional de los hombres. De esta forma empieza a perfilarse en la historia del pensamiento lo que constituye un largo discurrir frente a la justificación de las 
estructuras de poder estatal. A la luz de esta problemática, se han configurado las diferentes teorías contractualistas. El contrato social crea el cuerpo político, que es una representación moral establecida artificialmente por la voluntad de los hombres para beneficio propio; es decir, la propuesta de Hobbes (1994) parte de un fundamento ético y político, en el cual la educación constituye la base sobre la cual se crea y se mantiene el Estado. La función de la educación consiste en legitimar el Estado a través de la enseñanza y la transmisión de las leyes civiles. Para Hobbes, la enseñanza tenía que ser una prioridad dentro las múltiples tareas del Estado.

El poder político en la modernidad ya no se fundamenta en el poder de Dios ni en los textos bíblicos. Hobbes sabe que este poder deriva de otra instancia y por esto se pone la tarea de hacer de la política una ciencia, para mostrar el origen de ese poder. Para Strauss (2006), Hobbes acude al método de las ciencias naturales, tanto en el método como en el contenido, es decir, el resolutivo-compositivo de Galileo. Su fundamento epistemológico lo encuentra en la explicación de la naturaleza humana, en su individualidad conformando un todo social. Sin embargo, Strauss (2006) advierte que esta interpretación, que parece un hecho evidente, es cuestionable al examinarla más detenidamente, para él, Hobbes es consciente de las diferencias entre la ciencia natural y la filosofía política tanto en su contenido como en su método.

Ahora bien, Hobbes -como hombre moderno- sabe que para poder explicar el origen de la sociedad, necesita primero elaborar una concepción de hombre que no derive del orden religioso, sino que sea una concepción antropológica que le sirva de fundamento para forjar su noción social y política. De esta manera, el pacto social es el origen de la sociedad y la forma racional de comprensión de la misma. Pues la razón nos lleva a la búsqueda de la paz, para lo cual los hombres deben renunciar o trasferir sus derechos. Esta acción se denomina contrato, cuando el objeto del mismo se cumple de inmediato, y pacto, cuando implica una promesa hacia el futuro.

La mutua trasferencia de derechos entre dos o varias personas se llama contrato. Ahora bien, en todo contrato, o las dos partes cumplen inmediatamente lo que es objeto del mismo, de modo que no confían en nada una de la otra, o una cumple y otorga un crédito a la otra, o ninguna cumple. Cuando ambas partes cumplen inmediatamente, el contrato se termina tan pronto como se cumple. Cuando una de las partes otorga un crédito a la otra o ambas confían una en otra, la persona en la que la otra confía promete cumplir después. La promesa de este tipo se llama pacto. (Hobbes, 1966, p. 78)

Hobbes reconoce que la observancia y conocimiento de las leyes naturales no garantiza su cumplimento, por eso hacen falta leyes de otro tipo, estas son las leyes civiles que implican obligación y coerción. Es decir, la ejecución, la utilización y el uso legítimo 
de la fuerza para hacer cumplir lo pactado. De esta manera, la sociedad civil se convierte en una reducción voluntaria de los derechos naturales que en el estado de naturaleza se disfrutan sin restricción, para convertirse en socios en el pacto que se hace para la convivencia. Mientras subsista el derecho de todos a todo, subsistirá el estado de guerra; al reducir este derecho, se da comienzo a la sociedad civil.

El Estado será entonces quien tenga el poder supremo y, por tanto, el derecho a usar legítimamente la fuerza. Es el poder supremo, porque los hombres voluntariamente le han trasferidos el derecho de representarlos.

El estado, pues, ha de ser definido como una persona única cuya voluntad, en virtud de los pactos hechos entre muchos hombres, debe considerarse como la voluntad de todos ellos y que puede, por consiguiente, utilizar las fuerzas y los bienes de cada uno para la paz y defensa común. (Hobbes, 1966, p. 64)

Ahora bien, el Estado será entonces una multitud que consiente ceder su derecho a un hombre o a una asamblea. Este tendrá el derecho a representarlos a todos, de modo que la voluntad de este hombre o asamblea de hombres será la voluntad de todos. La finalidad de esto es mantener la paz y la seguridad, instituyendo así el Estado y el poder soberano. Poder que además es absoluto, esto significa, independiente de quienes realizaron el pacto.

Hace falta considerar que para que haya un comienzo de institución del Estado, cada miembro de la multitud debe consentir con los demás en que la voluntad de la mayoría se considere como voluntad de todos en los asuntos que alguien propone en la asamblea. Pues sin ello, una multitud nunca resolverá nada, dada la diversidad de caracteres y deseos de los individuos que la componen. Y, si alguien rehúsa su acuerdo, los demás, excluyéndole, no dejarán por eso de constituir entre sí un Estado. De ahí que el Estado conserva el derecho originario contra quien disiente, es decir, el derecho de guerra, como contra un enemigo [...]

Por consiguiente, en vista de que es necesario para la seguridad de los particulares, y sobre todo para la paz común, que el derecho de utilizar la espada para castigar se trasfiera a un individuo o a una asamblea, se debe entender necesariamente que ese individuo o esa asamblea tiene el derecho al poder soberano en el Estado. (Hobbes, 1966, pp. 127-128)

Este poder absoluto permite entonces que el soberano tenga la potestad no solo de castigar e impartir justicia, sino también el derecho a defender a todos de enemigos externos, a este mismo poder le corresponde hacer y dar a conocer reglas comunes para que todos puedan saber qué es lo suyo y lo ajeno, lo justo y lo injusto, lo honesto y lo deshonesto, lo bueno y lo malo, qué se puede enseñar y qué no, todo esto con el fin de no 
entorpecer la paz. Por esto, quien tiene este poder, tiene el derecho de usar los medios necesarios para mantener la paz y la seguridad, tanto interna como externamente.

Y como finalidad de esta institución del estado es la paz y defensa de todos, quien quiera que tenga derecho a procurar ese fin, lo tendrá también de procurar medios. Pertenece al derecho de cualquier hombre o asamblea que tenga soberanía el juzgar cuáles han de ser los medios de alcanzar la paz y de procurar la defensa, así como el tomar las medidas necesarias para que esa paz y esa defensa no sean perturbadas, $\mathrm{y}$ el hacer todo lo que crea pertinente para garantizar la paz y la seguridad, tanto en lo referente a medidas preventivas que eviten la discordia entre los súbitos y la hostilidad que pueda venir del exterior, como para recuperar esa paz y esa seguridad cuando se hayan perdido. (Hobbes, 1994, p. 149)

El poder se concentra en el soberano, constituyéndose así un Estado absolutista. El poder político se justifica aquí a partir de la institucionalización del Estado por medio del contrato o pacto social establecido por los mismos individuos, que ya en estas instancias son súbditos de un soberano. Ahora bien, hay que tener en cuenta que como todo en Hobbes, la educación está subsumida a esa idea de centralizar el poder, es decir, a esa concepción absolutista del Estado, y en este sentido la educación está supeditada y vigilada por el Estado y a la cual pretende mantener siempre a su servicio. La diferencia con el otro pilar del Estado, el monopolio de la fuerza (espada de la justica y espada de la guerra) que ejecuta los castigos, es que la educación no tendría un papel sancionador ni punitivo. En este aspecto, se podría entender la educación como un elemento de coacción racional en la conciencia interna de cada ser humano que ahora deviene como ciudadano.

\section{El sentido de la educación en Hobbes}

Esta idea de la protección de la propia vida lleva al establecimiento del pacto social, pues si está en todos, esta se vuelve en alguna media un fin común. Así, si su disposición para convivir con los otros es adquirida, lo hará a través de la educación y luego del establecimiento del pacto social. Para Hobbes (1994), la educación cumpliría entonces una función social y política, y esta función, en primera instancia, es mantener al hombre en la sociedad civil y no permitir que se devuelva a su condición natural, de la guerra de todos contra todos.

Hobbes (1966) sabe que tanto como en la sociedad como en la familia hay formas de dominación. En la familia, inicialmente el domino es de la madre o del padre y los niños son educados a partir de reglas y conceptos elaborados, de los cuales deducen consecuencias. Cuando el Estado se constituye desde la perspectiva hobbesiana, es decir, un Estado coercitivo, necesita de la educación en este mismo sentido. En otras palabras, la gente debe aprender y conocer las leyes del Estado y saber las consecuencias si las 
trasgreden (Castaño, 2000). El Estado debe instruir a los ciudadanos en lo que es lo justo y lo injusto, haciéndolos así más aptos para vivir en la paz y la seguridad. Por lo tanto, el conocimiento de las leyes debe tener un lugar principal en la educación, pues, según Hobbes (1994), su desconocimiento puede terminar siendo una excusa para quien las viole.

La educación vista desde esta perspectiva entraría a cumplir un papel plenamente preventivo, su función sería introducir la ley en los ciudadanos, además de promulgarla y hacerla conocer. Esta educación, en la concepción de Hobbes (1966), también buscaría un reconocimiento y aceptación racional por parte de los ciudadanos, no como una pura obediencia ciega, sino para que se vea su necesidad, la cual surge del abandono del estado de naturaleza y el paso al estado civil. La introyección de las leyes hace que la obediencia sea racional y se entienda y se dé el paso de un estado al otro.

Ahora bien, lo anteriormente señalado muestra que al plantearse el problema educativo se tiene que pensar también en la condición antropológica inherente a este, y en el caso de Hobbes sería qué clase de hombre se quiere formar dada su consideración antropológica del mismo, es decir, un hombre que no tiene la capacidad para vivir en sociedad, y que es precisamente la función que tendría que entrar a realizar la educación: darle la instrucción para desarrollar esas capacidades, es decir, tanto como para formar su capacidad cívica o ciudadanía, como para obedecer los mandatos del soberano.

[...] pero las sociedades civiles no son meras compañías; son asociaciones cuya realización exige promesa y pactos. Los niños y los incultos ignoran la fuerza de estos pactos, como ignoran su utilidad los que no tienen experiencia de los daños que resultan de la carencia de la sociedad. Los primeros, incapaces de entender lo que es una sociedad, no la pueden establecer, y los otros, por ignorar su utilidad, no procuran hacerlo. Luego, los hombres, ya que todos nacen niños, nacen sin aptitudes para la sociedad. Es más, muchos -si no la mayoría de ellos- nunca se vuelven aptos para ella, por debilidad de espíritu o por falta de educación. Y, sin embargo, tanto los niños como los adultos tienen naturaleza humana. Se debe concluir que el hombre no nace con aptitudes para la sociedad, sino que las adquiere por la educación. Además, aun cuando el hombre hubiera nacido con el gusto instintivo de la sociedad, no quiere decir que haya nacido apto para formar una sociedad. Una cosa es desear, otra cosa es ser capaz. (Hobbes, 1966, p. 64)

Ahora bien, ¿̇en quién recae la obligación de esta formación del ciudadano? Hobbes la pone en manos del Estado, específicamente en manos de quien administra el poder soberano y se manifiesta en sus deberes. Así, tanto en el Ciudadano como en el Leviatán, Hobbes dice lo siguiente: 
[...] Es, pues, deber de los que administran el poder soberano erradicar tales doctrinas de las mentes de los ciudadanos e insinuar en su lugar otras opuestas. Ahora bien, las opiniones se siembran en el espíritu de los hombres por enseñanza y no por mandato, por la claridad de las razones y no por el miedo a los castigos. Por consiguiente, las leyes, que deben obviar este mal, no se han de establecer contra quienes se equivocan, sino contra los errores. Estos errores, como afirmamos en el capítulo anterior, son incompatibles con la tranquilidad del estado; se han insinuado en la mente de los ignorantes desde las cátedras de los oradores, o a través de las conversaciones cotidianas de unos hombres que, por disponer de un amplio patrimonio, tuvieron tiempo para dedicarse a los estudios, y recibieron esas doctrinas de los preceptores que tuvieron, cuando adolecentes, en las academias públicas. De modo que quien quiere introducir una sana doctrina, debe empezar por las academias. Allí es donde se deben echar las bases verdaderas, y demostradas verdaderamente, de la ciencia política, para los adolescentes, imbuidos de ella, puedan luego instruir a la plebe pública y privadamente. Y lo harán con tanto entusiasmo y eficacia cuanto más seguros estén ellos mismos de la verdad de lo que enseñan y proclaman. En efecto si hoy en día se aceptan proposiciones por ser costumbre oírlas, aunque sean falsas y no más inteligentes que si se hubieran juntado vocablos sacados por suerte de una urna, iCuánto mejor acogerían los hombres por la misma razón doctrinas verdaderas, adaptadas a su inteligencia y a la naturaleza de las cosas! Creo, pues, que es oficio de los gobernantes supremos hacer consignar los verdaderos elementos de la doctrina política y mandar que se enseñen en todas las academias del Estado. (Hobbes, 1966, p. 209)

\section{Y en el Leviatán:}

[...] En segundo lugar, va contra su deber dejar que el pueblo ignore o esté mal informado acerca de los fundamentos y razones en que se basan esos derechos esenciales suyos; pues por causa de la ignorancia, los hombres pueden ser facialmente seducidos y llevados a oponer resistencia al soberano cuando el Estado requiera que los derechos se usen y se ejerciten. Y los fundamentos de estos derechos necesitan ser enseñados con diligencia y con verdad; pues no pueden mantenerse recurriendo a ley civil alguna, o por temor a un castigo leal. Pues una ley civil que prohíba la rebelión (y la rebelión es cualquier tipo de resistencia a los derechos esenciales de la soberanía) no obliga como ley civil, sino en virtud de la ley natural que prohíbe violar la fe. (Hobbes, 1994, p. 268)

De esta manera, la educación introduce al hombre egoísta en la consideración y el reconocimiento del otro, condición que le permitirá su propia realización. Este hombre supeditado a las leyes y al soberano trabajará con el único fin de mantener la paz y la convivencia. La educación debe llevar al hombre a una sumisión tal que no haya lugar para 
el deseo de cambio ni para sentir más admiración por un conciudadano que la que siente por su propio monarca y mucho menos para hablar mal de él (Hobbes, 1994, pp. 270-271).

Pero, cuál es el fundamento de Hobbes para establecer una educación completamente subordinada al Estado. El fundamento está, al parecer, en el principio de autoconservación que origina el pacto y lleva a la conformación del Estado y es precisamente la educación la que enseña el origen del primero y el mantenimiento del segundo, origen que no es otro que el deseo de conservar la vida y los bienes; esta racionalidad es la que tiene que seguir operando en el Estado civil para que la educación tenga sentido. La educación así se convierte, para Hobbes (1994), en un mecanismo para que los hombres trabajen por un bien común, esto es, conservar la sociedad civil y mantener parámetros que posibiliten la convivencia pacífica.

La educación para Hobbes (1994) se da bajo el signo de la obediencia y no bajo el signo de la autonomía, suprimir la obediencia en el Estado es llevarlo a que se disuelva, no hay peor falta que hablar mal de la autoridad. El miedo al soberano y la libertad son compatibles para Hobbes, considerar la libertad como una excepción a la ley es absurdo, pues la libertad y los derechos de los súbitos se dan dentro de las leyes civiles, lo que hay fuera de estas es una libertad absoluta en el estado de naturaleza, a la cual se debe renunciar. De esta manera, la educación debe buscar el uso de la razón, que lleva al reconocimiento que lo más racional es la obediencia al soberano y a las leyes para no caer nuevamente en el estado de naturaleza.

Muchas son las razones por las cuales el hombre llega a cometer crímenes, sus ambiciones, sus pasiones, riquezas, ansia de poder, que solo pueden ser evitadas con el uso de la razón o con la efectividad del castigo. Por esta razón, para mantener a los hombres en la sociedad se recurre a lo racional y al poder absoluto del Estado, y la educación sirve para esto en la medida en que ayuda a reconocer que la ley de la naturaleza deriva del uso de la razón, la cual enseña que si no hay un poder absoluto, los hombres vuelven a la lucha de todos contra todos. Por parte del soberano, los súbitos recibirán seguridad, y a través de las universidades y de los docentes como sus representantes se les instruirá en el beneficio que esto les trae. "Es, por tanto evidente, que la instrucción del pueblo depende enteramente de la correcta enseñanza de la juventud en las universidades" (Hobbes, 1994, p. 273). La universidad se convierte entonces en el medio de transmisión de la necesidad del poder político absoluto.

\section{Conclusiones}

Según Hobbes, lo que prevalece es la necesidad de dominio del cuerpo, el cuidado del mismo y satisfacer sus necesidades. Por eso, las leyes morales terminan siendo meras palabras si no van acompañadas de coacción. La moral queda reducida a una conducta 
social. La razón es que las leyes naturales o preceptos morales son anteriores a la leyes civiles y el hombre las cumple cuando desea y no recibe castigo por ello; sin embargo, por esto mismo son insuficientes para establecer la sociedad civil.

El fundamento de la moral de Hobbes no es pues precisamente la idea de lo bueno, se identifica más con el uso de la fuerza, con el instinto de supervivencia. Y aunque la justicia, en las reflexiones de Hobbes, aparece con el pacto, este no está por encima del derecho natural de la protección de la propia vida, que nos prohíbe hacer cosas para dañarla. El valor, el deber y el derecho de los hombres, es la conservación de la vida. No hay entonces una negación de la moral, pues la defensa de la vida se convierte en un valor supremo.

La sociedad civil no es entonces un acto de bondad, sino que surge del interés de la protección de la propia vida, pues al respetarla mutuamente se garantiza la seguridad de todos, ya que por voluntad propia hay una reducción en el uso de la fuerza física. De esta manera surge el pacto social de la disminución del uso de la fuerza que luego es transferida al soberano, quien tiene la obligación ahora de garantizar la vida de todos los socios.

En la concepción de Hobbes, la educación no tiene como papel fundamental el desarrollo del sentido crítico, pues está supeditada al poder absoluto del soberano. Esta educación solo busca mantener al soberano y al poder constituido con él. Su función es dar a conocer y trasmitir la ley de una generación a otra, excluyendo la posibilidad del cuestionamiento y, aunque es coherente con la propuesta política de Hobbes, no deja de ser riesgosa.

Desde Hobbes queda la idea de que antes de pensar en la sociedad y en la educación hay que pensar en el hombre y reflexionar desde el punto de vista antropológico sobre el mismo, solo esto le dará sentido a las dos primeras. La educación debe ser considerada como un proceso interactivo entre las personas y las estructuras sociales, pues se influyen mutuamente; pero esta interacción no es fija, puesto que siempre hay que estar meditando sobre qué tipo de ser humano, de sociedad y de educación se quiere.

\section{Referencias}

Altini, C. (2005). La fábrica de la soberanía: Maquiavelo, Hobbes, Spinoza y otros modernos. Buenos Aires: El Cuenco de Plata.

Bobbio, N. (1992). Thomas Hobbes. M. E. Romaní (trad.) México, D.F: Fondo de Cultura Económica.

Bobbio, N. (2003). Teoría general de la política. Madrid: Trotta.

Borón, A. (2000). La filosofía política moderna. De Hobbes a Marx. Buenos Aires: Clacsco. 
Cassirer, E. (1953). El problema del conocimiento en la filosofía y en la ciencia moderna. México, D.F.: Fondo de Cultura Económica.

Castaño, J. F. (2000). La educación en el planteamiento de Thomas Hobbes y algunas de sus implicaciones desde la perspectiva de la teoría crítica. Revista Educación y Pedagogía, 12(26), 181-187.

Hobbes, T. (1966). El ciudadano. Caracas: Facultad de Derecho, Universidad Central de Caracas.

Hobbes, T. (1992). Diálogo entre un filósofo y unjurista y escritos autobiográficos. M. A. Rodilla (trad.) Madrid: Tecnos.

Hobbes, T. (1994). Leviatán I. C. Mellizo (trad.) Barcelona: Altaya.

Hobbes, T. (2005). Elementos de derecho natural y político. D. N. Pavón (trad.) Madrid: Alianza.

Macpherson, C. (1970). La teoría política del individualismo posesivo de Hobbes a Locke. J. Capella (trad.). Barcelona: Fontanella.

Medina, I. (2014). Política, democracia y liberalismo en el origen de la época moderna. Espiral, Estudios sobre Estado y Sociedad, 21(60).

Santillán, J. F. (1998). Hobbes y Rousseau. Entre la autocracia y la democracia. México, D.F.: Fondo de Cultura Económica.

Sierra, H. H. (2011). Sobre la condición humana en la teoría del Estado de Hobbes. Cuestiones de Filosofía, (13), 83- 93.

Strauss, L. (2006). La filosofía política de Hobbes: su fundamento y su génesis. Buenos Aires: Fondo de Cultura Económica. 